\title{
Evaluating the Efficacy of Vertebral Axial Decompression Therapy in Treatment of Patients with Chronic Lower Back Pain: A Systematic Review
}

\author{
James McKivigan”, Brittany Krisak, Brittni Vogel, Ashley Harrington, Van Nguyen \\ School of Physical Therapy, Touro University, Henderson, USA \\ Email address: \\ james.mckivigan $a$ tun.touro.edu (J. McKivigan), pa18.brittany.krisak@nv.touro.edu (B. Krisak), \\ mhs16.brittni.vogel $a$ nv.touro.edu (B. Vogel), pa19.ashley.harrington $a$ nv.touro.edu (A. Harrington), \\ pa19.van.nguyen $a$ nv.touro.edu (V. Nguyen) \\ ${ }^{*}$ Corresponding author
}

\section{To cite this article:}

James McKivigan, Brittany Krisak, Brittni Vogel, Ashley Harrington, Van Nguyen. Evaluating the Efficacy of Vertebral Axial Decompression Therapy in Treatment of Patients with Chronic Lower Back Pain: A Systematic Review. Rehabilitation Science. Vol. 4, No. 2, 2019, pp. 25-34. doi: 10.11648/j.rs.20190402.12

Received: July 22, 2019; Accepted: September 29, 2019; Published: October 25, 2019

\begin{abstract}
The primary objective of the study was to explore the effectiveness of Vertebral Axial Decompression (VAX-D) in treating patients with chronic low back pain (CLBP) as a safe and competent therapeutic method. Also, to determine the quality of life in alleviating chronic lumbar pain using mechanical Lumbar traction force applied to the lumbar spine. A systematic review and meta-analysis involving detailed literature survey on Vertebral Axial Decompression (VAX-D) therapy for patients with chronic low back pain were conducted in three databases namely MEDLINE, EMBASE and Cochrane Library from (January 1994 to February 2019). Studies supporting the outcomes with qualitative statistical analysis on chronic low back pain and Lumbar traction were retrieved. We retrieved sixteen randomized controlled trials (RCTs) for systematic review, and 6 studies were found to be eligible for inclusion in meta-analysis with a sample size of 486 patients receiving Lumbar traction. Among them, one study was found to be high quality that detailed the positive relationship between reduction of pain intensity after VAX-D therapy. However, most of the studies are unsuccessful in demonstrating an improvement towards the patient's mobility or quality of life. There is no reliable indication of the efficacy of VAX-D therapy for chronic low back pain patients. Studies on VAX-D had methodological errors and inadequate data for profound statistical analysis. Further, there was no evidence to show the dosage requirement, patient position, and settings on the VAX-D table that led to observed outcomes. Any prospect of research focusing on LBP morbidity should enable to distinguish between symptom duration and pattern with accurate standard methods. Therefore, more studies validating the effective treatment strategies in the management of patients with chronic low back pain are warranted.
\end{abstract}

Keywords: Vertebral Axial Decompression, Chronic Low Back Pain, Lumbar Traction, Lumbar Spine, Quality of Life, Randomized Controlled Trials

\section{Introduction}

Chronic low back (CLBP) exists as one of the significant causes of disability worldwide. CLBP is a well-recognized public health burden, and treatment cost has peaked progressively during four decades. Although there is an increasing prevalence of CLBP [1], however, their effective treatment modalities remain elusive. CLBP is experienced by the illnesses affecting the bony lumbar spine, ligaments around the backbone and discs, intervertebral discs (discs between the vertebrae), spinal cord and nerves, muscles of the low back, internal organs, and the skin covering the lumbar area. The early LBP is a symptom, not a disease, and it has a wide range of causes. Chronic LBP was prevalent and was found to be approximately $84 \%$. In most of the cases, they are mild to moderate and tentative to repeat without affecting the daily activities, and thus, the majority of the individuals with LBP do not seek medical care. In the United 
States, $10-15 \%$ of acute LBP becomes chronic; $1 \%$ can progresses to permanent disability consuming up to $90 \%$ of health care and social costs for treatment of low back pain [2]. Despite the acceptance of low back pain disability and provision of disability benefits for sufferers in society have significantly contributed to the growing trend of LBP disability.

CLBP was identified as the third most common cause for physician visits in males and sixth in females accounting for $6 \%$ of all physician visits. One in every three physiotherapist consultations, $2.5 \%$ of drug prescriptions, and $5-10 \%$ of imaging studies were for CLBP [3]. A report from the USA denoted that approximately 1 in 4 adults face the burden of low back pain that lasted at least 24 hours within the previous 3 months and about $8 \%$ of individuals experience at least one incidence of severe acute LBP within a year period $[4,5]$. Studies conducted on CLBP, reports that around 13\% of work-related injuries result in LBP disability in younger individuals $(<45$ years) and the common leading cause for sick leaves.

Also, low back pain is the primary cause of inactivity and unsatisfactory work progress resulting in a vast economic burden on individuals; families, communities, industry, and governments' worldwide [6-9]. In 1998, overall health care incremental costs were assessed to be $\$ 26.2$ billion that is directly attributed to LBP in United States [10].

Lumbar traction is an effective conservative method used in the treatment of lumbar disc herniation. It is routinely done by self or in combination with other therapies for the management of lumbar sciatica $[11,12]$. A better relief to vertebrae separation has been shown by traction technique, which could provide radicular symptoms relief by directly removing pressure or forces of contact from affected neural tissue. It may also have particular benefits by stretching soft tissues [13].

The mechanisms of action of LT are mediated by mechanical force through a separation of intervertebral motion segments [14-16] leading to a substantial decrease in intradiscal pressure [17-19], and neurophysiological, through the modulation of the pain pathways by equivalence with spinal manipulations [20]. Vertebral Axial Decompression (VAX-D) technique uses significant distractive forces to the lumbar spine in a graduated, progressive manner using electric components and an advanced computer control system [21].

An alternative or additional treatment for secondary radicular lumbosacral pain to herniation disc is traction. A motor pulley was designed to provide a segmental mechanized distraction that resources this sort of nonsurgical decompression in the spinal region which can be delivered either in an oscillatory or static fashion for a fixed period. The elimination of frictional resistance by split table design between table and patient, and provides manageable, effective decompression to the spinal region and a noticeable reduction in intradiscal pressure [21].

Approximately after one month of treatment, only patients who received VAX-D sessions every alternate day had a
$47.4 \%$ progress in their pain intensity; with improvements functionally by $17.7 \%$. After three months, it is further reduced by $79.4 \%$ of their pain intensity, and their improvements in functional were found to be $50.8 \%$. However, the proportion of the increase in function and pain was significantly different in various cases.

A distinct retrospective study also showed benefit with motorized spinal decompression over standard pelvic traction [22]. Beattie et al. conducted an 8-week course of VAX-D and observed significant outcome improvements for all the post-intervention scores when compared with the pre-intervention score [23]. Despite these projected neurologic or/and mechanical mechanisms of action, currently, there is no clear consensus regarding the amount of force to apply in LT interventions. In this connection, popular retrospect articles report mainly that evidence that is limited or conflicting to support the valuable effect of Lumbar Traction versus sham or no treatment in patients with lumbar sciatica [24, 25]. Thus, the outcomes found from the studies are somewhat problematic to interpret, given the heterogeneity of levels, modalities, durations of tractions, treatment duration, and medical status of patients [26-28].

Cholewicki et al. have reported that antagonistic trunk muscle co-activation is necessary to provide mechanical stability to the lumbar spine around a neutral posture that results in an improved response to increasing the axial load on the needle [29]. Thus, agonist-antagonist muscle coactivation resulting from vibration therapy might have improved the patient's motor control strategy to enhance joint stability and movement accuracy.

Further, traction therapy along with spinal decompression, can functionally enhance the extension strength in lumbar and in both dynamic and static balance which are required to endure a spinal position neutrally. Both vibration and traction therapy has been associated with reducing pain intensity in patients with LBP. Recently, Wang et al [30] stated that traction applied to patients while lying on a table in combination with $12 \mathrm{~Hz}$ of vibration was significant in decreasing muscle fatigue of the lumbar erector spinae.

Six studies were analyzed in groups determined by similarity of patients, interventions, comparisons, and outcomes to perform the meta-analysis. This study critically evaluates data from randomized controlled trials (RCTs) using VAX-D technique for people with CLBP. The primary goal of this study is to compile a substantial amount of peer-reviewed journal articles and provide an unbiased and non-conflicting perspective on the efficacy of the VAX-D system.

\section{Materials and Methods}

An extensive search of scientific articles in reputable peerreviewed journals was done to compile approximately 50 articles. The series of literature searches from January 1994 to February 2019 included using search engines PubMed, EBSCO multi-search, and Google Scholar electronic 
databases. Keywords used included vertebral axial decompression, efficacy, lumbar traction, VAX-D, low back pain, and therapy. Keywords were combined and used to collect related data. First, abstracts were screened, and if an item satisfied our inclusion criteria, it was retrieved for full article use. Additional materials were also extracted by searching cited references for related content. Manual searches of insurance company policies regarding VAX-D coverage were also included. The search was limited to only published papers in the English language.

\subsection{Study Selection}

The articles that met our inclusion criteria were prepared for analysis using Purdue Owl as consultation for writing, as well as insight into critically dissecting journal articles. To compare and compile the necessary information for our systematic review, we examined the following qualities of each item: blinding of subjects, the method of subject selection, experimental outcomes, comparison of experimental and control groups, and avoidance of bias. A manual search for additional references was also performed. Therefore, there could be some publication and language bias in the review. Initially, we screened 50 abstracts, but only 23 articles were found to fit our inclusion criteria as outlined in Table 1. Seven of 23 were disqualified for a variety of reasons, including: a single case report $(n=1)$, a retrospective survey $(n=1)$, studies using a machine other than VAX-D $(\mathrm{n}=2)$, an article that was not peer-reviewed $(\mathrm{n}=1)$, an opinion paper $(n=1)$, and a study with no methodology $(n=1)$. Therefore, we retrieved 16 relevant articles for our literature analysis. Figure 1 shows the stages of study selection and the number of studies at each step.

Inclusion criteria contained scientific journal articles and writings that identified vital elements about the aims of this systematic review. Participants included in the analysis were over the age of 18 and had the clinical diagnosis by a licensed physician and confirmed by diagnostic imaging of chronic low back pain with or without radiculopathy or sciatica, herniated disc, degenerative disc disorder, or facet injury. The study also had to use at least one of four primary outcomes: pain, disability index questionnaire, quality of life, and an overall measurement of improvement.

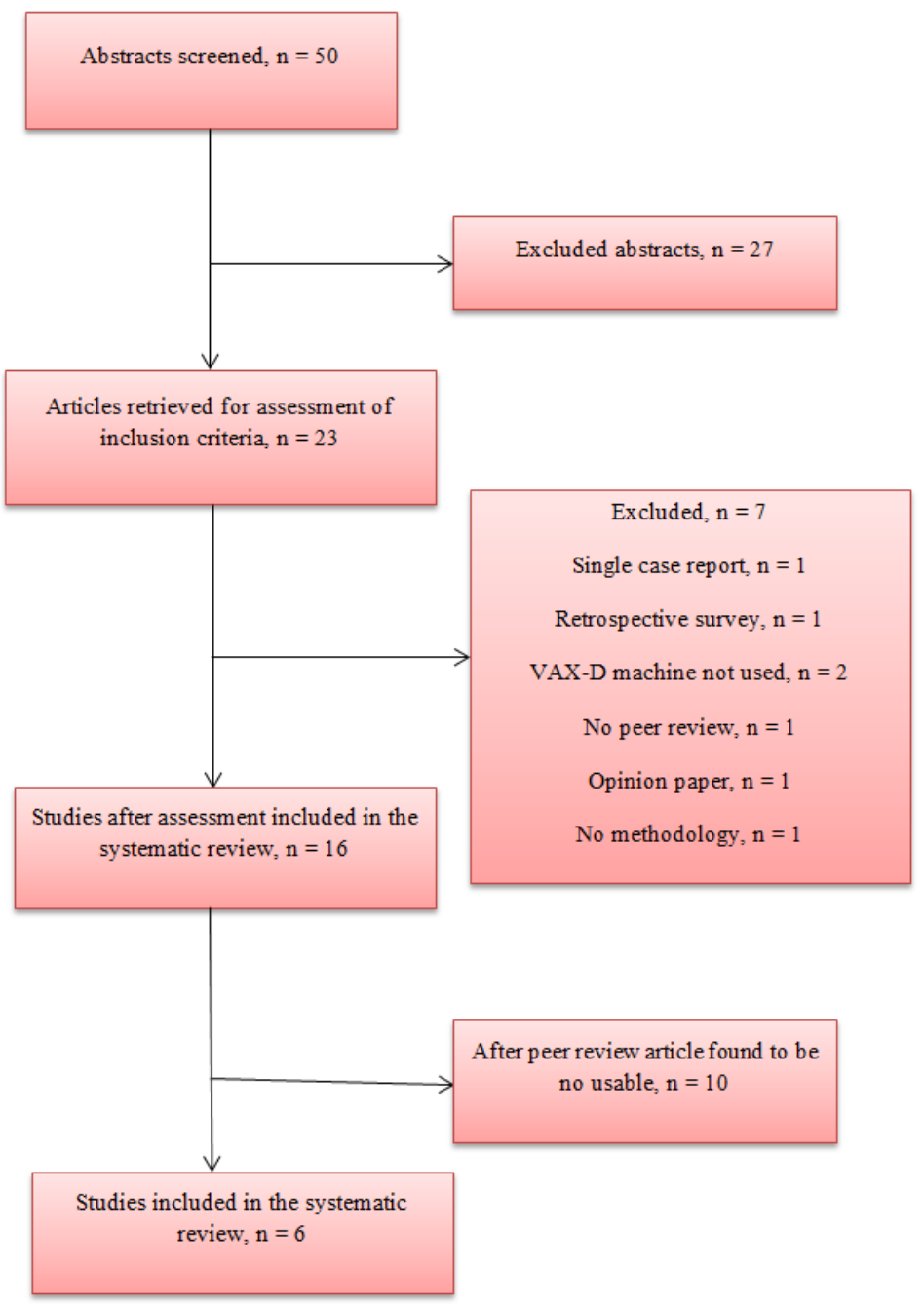

Figure 1. Flow chart of study selection. 
Exclusion criteria consisted of articles published before 1994 and in languages other than English. Studies that admitted conflict of interest with the VAX-D company or involved motorized cervical traction and other methods of vertebral decompression that were mechanically controlled.
If a study included patients with surgical hardware of the spine, the use of materials produced by a manufacturer other than VAX-D, LBP caused by specific pathological origin (infection, osteoporosis, etc.), or was an isolated case study were excluded.

Table 1. Characteristics of Selected Studies.

\begin{tabular}{|c|c|c|c|}
\hline Author and year & Clinical Dx & Course of $T x$ & Additional therapies used with VAX-D \\
\hline $\begin{array}{l}\text { Beattie et al } 2007 \\
{[23]}\end{array}$ & $\begin{array}{l}\text { Diagnostic imaging evidence of a } \\
\text { degenerative and/or herniated } \\
\text { intervertebral disk. }\end{array}$ & $\begin{array}{l}\text { Patients had an eight-week course of prone VAX- } \\
\text { D treatment consisting of five } 30 \text {-minute } \\
\text { sessions/week for four weeks, followed by one } \\
\text { 30-minute session/week for four additional } \\
\text { weeks. }\end{array}$ & N/A \\
\hline $\begin{array}{l}\text { Naguszewski et al } \\
2001[31]\end{array}$ & $\begin{array}{l}\text { Clinical diagnosis of LBP and } \\
\text { unilateral or bilateral L5 or S1 } \\
\text { radiculopathy confirmed by CT } \\
\text { or MRI. }\end{array}$ & Treatment sessions varied from 10 to 35 minutes. & $\begin{array}{l}\text { Bilateral lower extremity dermatomal } \\
\text { somatosensory evoked potentials } \\
\text { (DSSEPs). }\end{array}$ \\
\hline Ramos 2004 [21] & $\begin{array}{l}\text { Chronic LBP with or without leg } \\
\text { pain, confirmed by MRI or CT } \\
\text { scan. }\end{array}$ & $\begin{array}{l}15 \text { distraction and relaxation cycles per day five } \\
\text { days/week for either two or four weeks. }\end{array}$ & $\begin{array}{l}\text { Medication allowed as needed. All other } \\
\text { treatment was stopped. }\end{array}$ \\
\hline Ramos 2004 [21] & $\begin{array}{l}\text { Disc herniation at one or more } \\
\text { levels confirmed by MRI. }\end{array}$ & $\begin{array}{l}\text { Measuring intradiscal pressure by inserting the } \\
\text { cannula into the nucleus pulposus of the disc }\end{array}$ & Not indicated. \\
\hline $\begin{array}{l}\text { Sherry et al } 2001 \\
{[32]}\end{array}$ & $\begin{array}{l}\text { Chronic LBP, associated leg pain, } \\
\text { and Confirmed disc protrusion or } \\
\text { herniation on CT or MRI. }\end{array}$ & $\begin{array}{l}30 \text {-minute treatment session, } 15 \text { cycles of } \\
\text { decompression/relaxation, } 5 \text { days/week for } 4 \\
\text { weeks. }\end{array}$ & $\begin{array}{l}\text { Non-narcotic pain relievers, no PT, } \\
\text { injections or any other treatments allowed. }\end{array}$ \\
\hline $\begin{array}{l}\text { Tilaro et al. } 1999 \\
\text { [33] }\end{array}$ & $\begin{array}{l}17 \text { patients with radiculopathy } \\
\text { and abnormal sensory function. }\end{array}$ & $\begin{array}{l}\text { Present Perception Threshold evaluations on } 22 \\
\text { nerves of peripheral were taken after and before } \\
\text { VAX-D. }\end{array}$ & Unknown \\
\hline $\begin{array}{l}\text { Beattie et al } 2007 \\
{[23]}\end{array}$ & $\begin{array}{l}\text { Diagnostic imaging evidence of a } \\
\text { degenerative and/or herniated } \\
\text { intervertebral disk. }\end{array}$ & $\begin{array}{l}\text { Patients had an eight-week course of prone VAX- } \\
\text { D treatment consisting of five } 30 \text {-minute } \\
\text { sessions/week for four weeks, followed by one } \\
\text { 30-minute session/week for four additional } \\
\text { weeks. }\end{array}$ & N/A \\
\hline $\begin{array}{l}\text { Naguszewski et al } \\
2001[31]\end{array}$ & $\begin{array}{l}\text { Clinical diagnosis of LBP and } \\
\text { unilateral or bilateral L5 or S1 } \\
\text { radiculopathy confirmed by CT } \\
\text { or MRI. }\end{array}$ & Treatment sessions varied from 10 to 35 minutes. & $\begin{array}{l}\text { Bilateral lower extremity dermatomal } \\
\text { somatosensory evoked potentials } \\
\text { (DSSEPs). }\end{array}$ \\
\hline
\end{tabular}

Table 1. Continued.

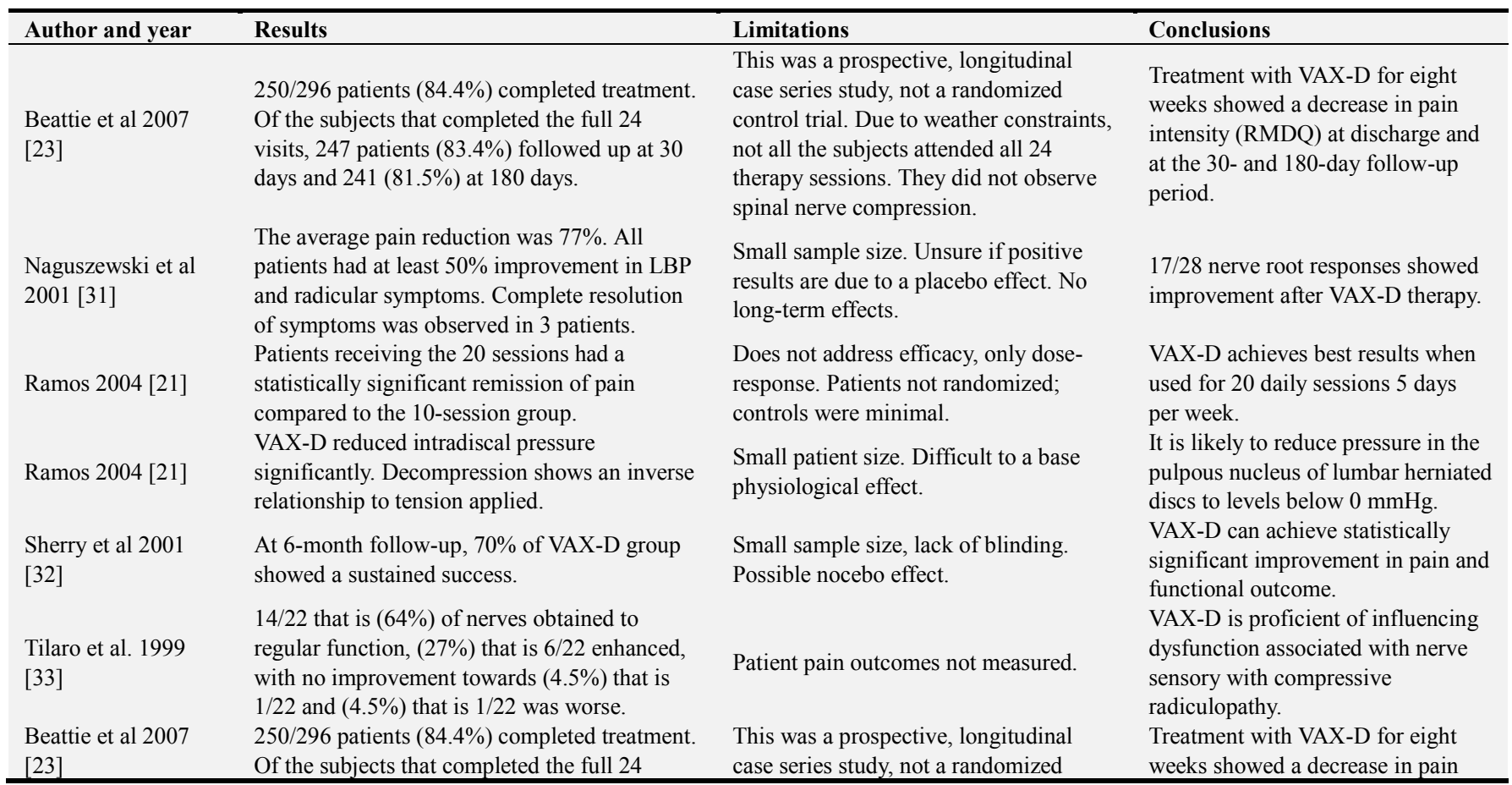




\begin{tabular}{|c|c|c|c|}
\hline Author and year & Results & Limitations & Conclusions \\
\hline & $\begin{array}{l}\text { visits, } 247 \text { patients }(83.4 \%) \text { followed up at } 30 \\
\text { days and } 241(81.5 \%) \text { at } 180 \text { days. }\end{array}$ & $\begin{array}{l}\text { control trial. Due to weather constraints, } \\
\text { not all the subjects attended all } 24 \\
\text { therapy sessions. They did not observe } \\
\text { spinal nerve compression. }\end{array}$ & $\begin{array}{l}\text { intensity (RMDQ) at discharge and } \\
\text { at the } 30 \text { - and 180-day follow-up } \\
\text { period. }\end{array}$ \\
\hline $\begin{array}{l}\text { Naguszewski et al } \\
2001[31]\end{array}$ & $\begin{array}{l}\text { The average pain reduction was } 77 \% \text {. All } \\
\text { patients had at least } 50 \% \text { improvement in LBP } \\
\text { and radicular symptoms. Complete resolution } \\
\text { of symptoms was observed in } 3 \text { patients. }\end{array}$ & $\begin{array}{l}\text { Small sample size. Unsure if positive } \\
\text { results are due to a placebo effect. No } \\
\text { long-term effects. }\end{array}$ & $\begin{array}{l}17 / 28 \text { nerve root responses showed } \\
\text { improvement after VAX-D therapy. }\end{array}$ \\
\hline
\end{tabular}

Abbreviations: N/A, not available; Tx, Treatment; Dx, Diagnosis. Only articles that were primary research articles were included. Systematic reviews did not appear in this table.

\subsection{Meta-Analysis}

Meta-analysis was performed in Review Manager (RevMan) [Computer program] Version 5.3 using the usercontributed commands forest plot and funnel plot. Standardized mean differences (SMDs) and subsequent Odd's ratio (OR) were calculated for studies that are included using standard deviations, means, and sample sizes reported in the relevant publications. A negative SMD relates to a score with lower back pain being associated with the group.

\subsection{Post Hoc Sensitivity Analysis}

Effective evaluations were pooled using random model effects. Unlike fixed model effects, which assume that every study evaluates the same size effect, a random model effect considers that every study evaluates a diverse effect. The data presented in our study were drawn from a particular common distribution. Additionally, random sampling error, variances could also be due to differences between study designs and populations. The $I^{2}$ statistic was also considered, which evaluates inconsistency between proximity and is independent of the size sample.

The inclusion depends on only the studies reporting results at initial follow-up and the last follow-up time points as a comparison in the primary analysis. However, to maximize the comparability, the studies included were used to test the intensity of pain measured after VAX-D treatment (between reduced pain Vs. increased pain). One sensitivity analysis included only studies which collected pain measurements immediately post-treatment. While other sensitivity analyses as being at a high RoB were considered with the effect of included studies.

\section{Results}

The search strategy initially identified 50 studies, 27 of which were excluded when limits were applied (clinical trials with humans, full-text English or Spanish language, and exceeds selected years). The residual 23 articles were reviewed; of these, 14 were excluded for being duplicated. Seven of 23 were disqualified for a variety of reasons, including: a single case report $(\mathrm{n}=1)$, a retrospective survey $(\mathrm{n}=1)$, studies using a machine other than VAX-D $(\mathrm{n}=2)$, an article that was not peer-reviewed $(n=1)$, an opinion paper $(n=1)$, and a study with no methodology $(n=1)$. Therefore, 16 relevant articles were used in our literature analysis. Finally,
16 articles were found to satisfactory and had an adequate methodological quality and were consequently selected for the review and analysis of their results and conclusions. The procedure of the investigation is summarized in Figure 1.

\subsection{Risk of Bias}

All the trials contained in our study were randomizedcontrolled parallel studies. The method of randomization was reported in five trials [21, 23, 32, 33]. Beattie et al [23] study determined short- and long-term outcomes by using the VAX-D protocol after administration of prone traction. The method was applied to a sample of patients with activitylimiting LBP that had been refractory to at least two sessions of previous, non-operative interventions, with a lack of randomized clinical trials.

Naguszewski et al [31] study used dermatomal somatosensory suggested potentials (DSSEPs) to determine lumbar root decompression following VAX-D therapy. The selected subjects are DSSEPs satisfied patients undergoing lumbar spine surgery and the randomized trial was not sensed in this study. However, the intervention and other follow-ups were suitable for this analysis. The Ramos [21] study compared the effects of two dosage regimens of VAX-D treatments (low and high) on the analogue scale for low back pain in patients. The study was a prospective randomized control trial conducted on CLBP patients advised to seek neurosurgical care after failing standard medical therapy. Sherry et al [32] conducted a randomized controlled trial that made attempts to address the question of appropriateness and efficacy of vertebral axial decompression (VAX-D) therapy. Tilaro [33] study proposed to determine whether VAX-D therapy could externally decompress the nerve root, with a randomized controlled trial between surgically and conservatively treated patients.

All the five studies included in the analysis reported the time of follow-up; three studies have eight weeks course of lumbar traction [23, 31,33] one reported for 4-6 weeks [32], and other study reported 6-12 weeks [21] For each included study, the outcomes listed in the methods section were all reported. Notable publication bias can be observed since most of the included and excluded studies were published in English or Chinese, although we have attempted to do our best to search all probable literature without any language restrictions and have contacted investigators to get more information. The studies included used different range of cutoff times to a particular intensity of pain although it was 
clearly stated that pain was persisting, or recurring, at the site of shingles at least. We have not restricted to include the studies using the same definition in order not to introduce more missing data. One (Sherry et al [32]) of the trials were rated as at low risk of bias, one (Naguszewski et al [31]) as high risk of bias, and another two (Ramos [21]; Tilaro [33]) has an unclear risk of bias (Figure 2).

\subsection{Results from the Pain Outcome Measures (Reduced Pain Vs. Increased Pain)}

Sherry et al [32] study, a high-quality RCT involving traction was found to have statistically significant differences on measures of pain, overall improvement with the duration of follow-up ranging from 1 to 8 weeks. Duration of LBP in patients was observed for 6 months (chronic) in Beattie et al [23], for $>3$ months (sub-acute and chronic) in Sherry et al [32] studies. Six studies have been analyzed to determine the pain outcome measures after VAX-D treatment. Five studies reported the outcome of post-treatment improvement with standard mean groups showing lower levels of pain during follow-up. One of the reviews of Ramos [21] reporting low dosage group showed improvement in pain relief and found to be reduced when compared to the high dosage group.

The analysis of Beattie et al [23] showed significant improvements for all post-intervention outcome scores when compared with pre-intervention scores $(p<0.01)$. In Naguszewski et al [31] study, the overall measure of pain from seven patients displayed significant improvement in post-treatment after VAX-D therapy for six studies and the random-effects model was 2.22 (95\% CI, 0.69 to 7.13), corresponding to a reduction in pain among participants at follow-up (Figure 3). Analysis of $I^{2}$ statics suggests inadequate evidence against the assumption of homogeneity between effect estimates $\left(I^{2}=91 \%, \mathrm{p}=0.18\right)$.

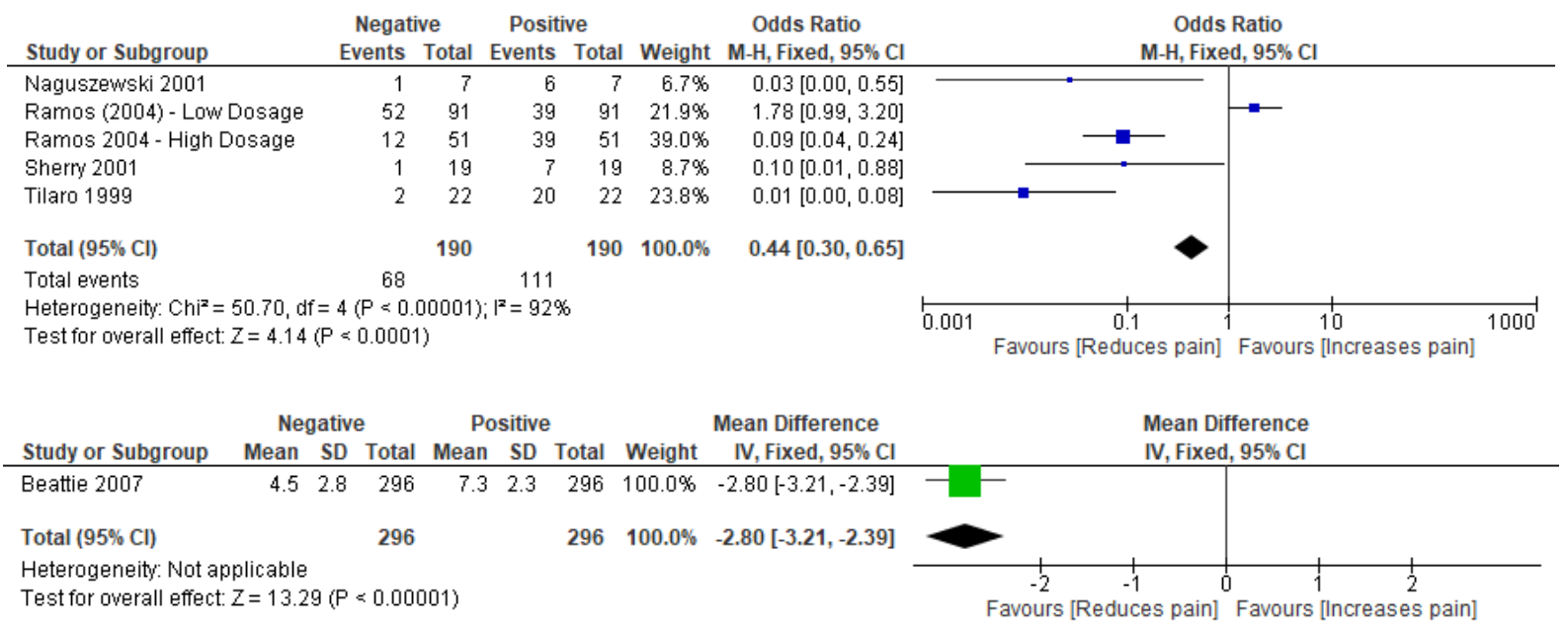

Comparison of groups underwent VAX-D therapy to determine pain intensity.

Figure 2. Analysis 1: Forest plot.

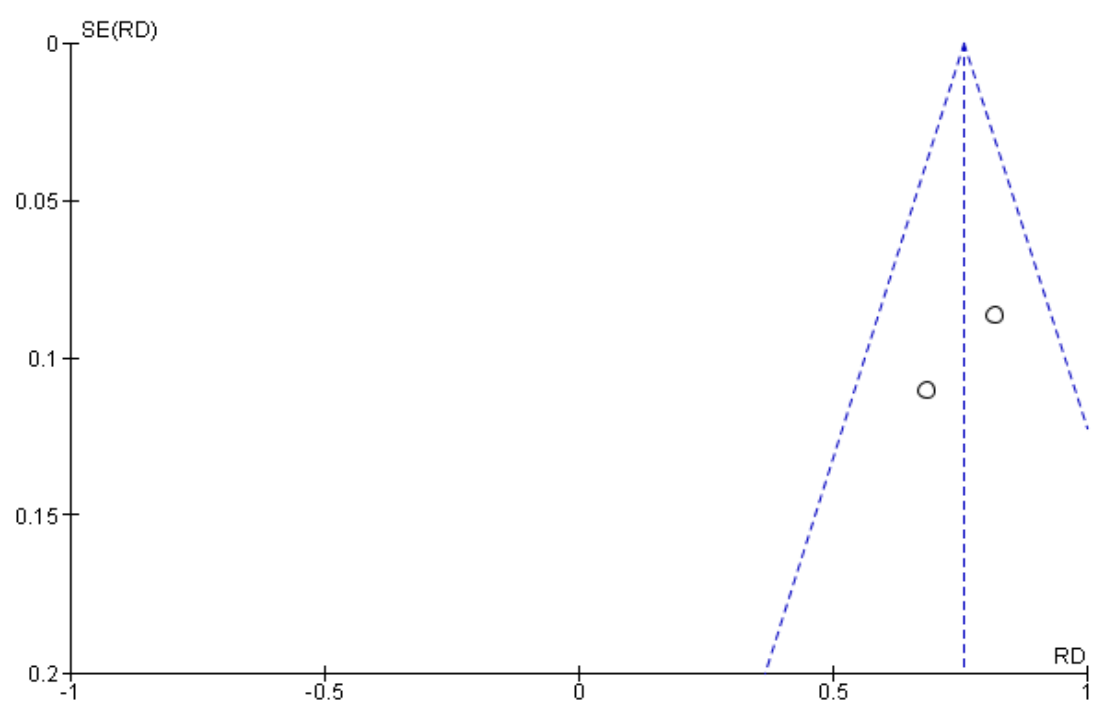

Comparison of groups underwent VAX-D therapy to determine pain intensity.

Figure 3. Analysis 2.1 Funnel plot. 


\subsection{Pain Intensity Measurement Immediately After VAX-D Treatment}

The three trials, Sherry et al [32]; Tilaro [33] and Beattie et al [23] involved traction. Beattie et al [23] trial involving VAX-D suggested a favorable association between the prone friction applied and VAX-D from the preliminary outcome measures used in this study (Figure 4). However, the study is deficient of a randomized control group, and thereby, it is not possible to establish a relationship between the traction applied with VAX-D and outcome. In Sherry et al [32] study, all the VAX-D group patients were recorded with some improvement in their pain levels, seven $(70 \%)$ have shown sustained success (i.e., they still meet the criteria for the successful outcome).

From Tilaro [33] study, the overall improvement was $67 \%$ that is statistically significant $(p<0.05)$ since the study evaluated VAX-D therapy outcome with regards to CPT score of normal nerve functioning. According to the study, Sixty-four percent $(64 \%)$ of the patients achieved complete recovery of neurologic function, and it was found that risk ratio of $0.04(95 \% \mathrm{CI}, 0.00$ to 0.58$)$ significantly greater than the previously reported study. The overall pain intensity measurement immediately after VAX-D treatment from the three studies showed significant improvement from lower back pain with $I^{2}$ statistic $=0 \%, \mathrm{P}=0.51$, and the test for overall effect $Z=4.22$ (Figure 5).

\begin{tabular}{|c|c|c|c|c|c|c|c|c|c|c|c|c|}
\hline \multirow[b]{2}{*}{ Study or Subgroup } & \multicolumn{3}{|c|}{ Negative } & \multicolumn{2}{|c|}{ Positive } & \multicolumn{3}{|r|}{ Odds Ratio } & \multirow{2}{*}{\multicolumn{4}{|c|}{$\begin{array}{c}\text { Odds Ratio } \\
\text { M-H, Fixed, } 95 \% \mathrm{Cl}\end{array}$}} \\
\hline & Ever & & Total & Events & To & tal W & Weight & M-H, Fixed, $95 \% \mathrm{Cl}$ & & & & \\
\hline Sherry 2001 & & 2 & 22 & 20 & & 22 & $58.0 \%$ & $0.01[0.00,0.08]$ & & 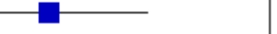 & & \\
\hline Tilaro 1999 & & 0 & 19 & 13 & & 19 & $12.0 \%$ & $0.01[0.00,0.24]$ & & & & \\
\hline Total $(95 \% \mathrm{Cl})$ & & & 41 & & & 4110 & $0.0 \%$ & $0.01[0.00,0.06]$ & & & & \\
\hline Total events & & 2 & & 33 & & & & & & & & \\
\hline $\begin{array}{l}\text { Heterogeneity: } \mathrm{Chi}^{2}= \\
\text { Test for overall effect }\end{array}$ & $\begin{array}{l}=0.01 \\
Z=5\end{array}$ & $\begin{array}{l}\mathrm{df}=1 \\
.04(P\end{array}$ & $\begin{array}{l}1(P=0 \\
P<0.00\end{array}$ & $\begin{array}{l}0.91) ; 1^{2} \\
0001)\end{array}$ & $=0 \%$ & & & & 0.001 & Favours [Reduces pain] & Favours [Increases pain] & 1000 \\
\hline & & gativ & & & sitive & & & Std. Mean Differen & & Std. Mea & an Difference & \\
\hline Study or Subgroup & Mean & SD & Total & Mean & SD & Total & Weight & IV, Fixed, 95\% & $\% \mathrm{Cl}$ & IV, Fixe & $\mathrm{ed}, 95 \% \mathrm{Cl}$ & \\
\hline Beattie 2007 & 5 & 2.3 & 296 & 4.7 & 2.6 & 296 & $100.0 \%$ & $0.12[-0.04,0$ & .28] & & - & \\
\hline Total $(95 \% \mathrm{Cl})$ & & & 296 & & & 296 & $100.0 \%$ & $0.12[-0.04,0$. & .28] & & & \\
\hline $\begin{array}{l}\text { Heterogeneity: Not ap } \\
\text { Test for overall effect: }\end{array}$ & $\begin{array}{l}\text { olicable } \\
Z=1.48\end{array}$ & & $0.14)$ & & & & & & & $\begin{array}{lc}1 & 1 \\
-1 & -0.5 \\
& \text { Favours [lncreases pain }\end{array}$ & $\begin{array}{cc} & 1 \\
0 & 0.5 \\
\text { n] } & \text { Favours [Reduce }\end{array}$ & \\
\hline
\end{tabular}

Comparison of groups' pain intensity with pain measurement immediately after VAX-D treatment.

Figure 4. Analysis 2: Forest plot.

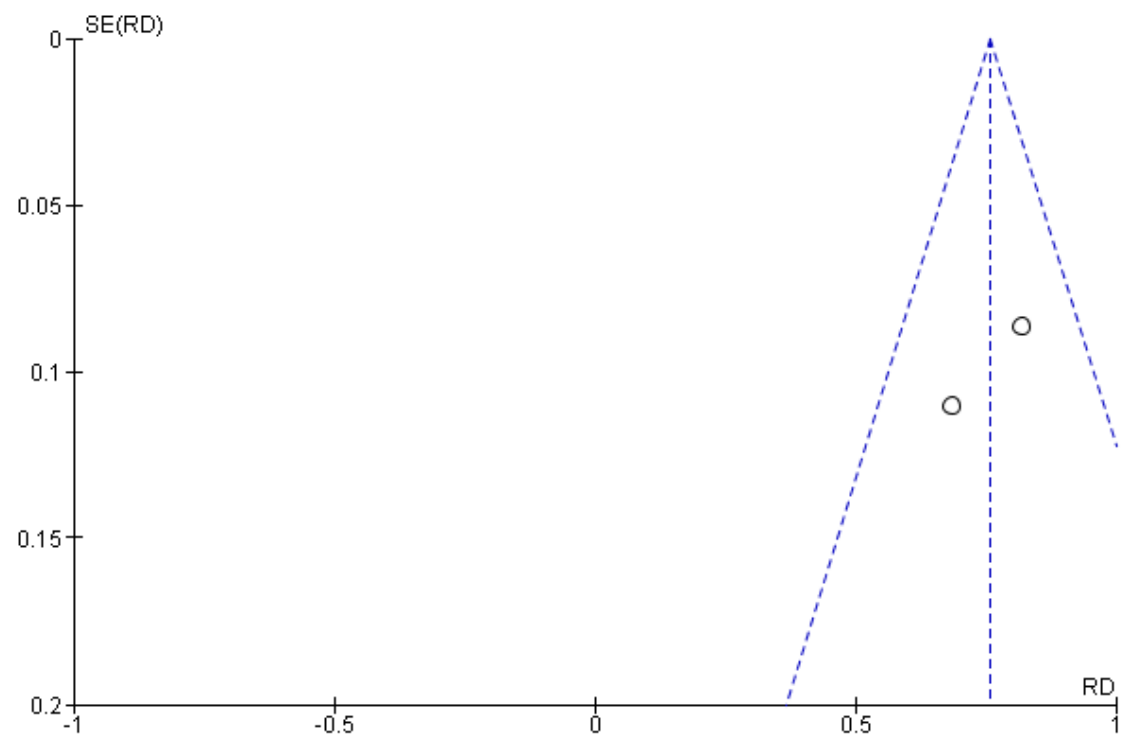

Comparison of groups' pain intensity with pain measurement immediately after VAX-D treatment.

Figure 5. Analysis 2: Funnel plot.

\subsection{Pain Intensity Measurement During Follow-up After VAX-D Treatment}

All the five trials Sherry et al [32]; Naguszewski et al
[31]; Ramos [21] (Low dosage); Ramos [21] (High dosage); Beattie et al [23] involved traction with a follow-up for pain intensity measurement. From Naguszewski et al [31] study, the majority of the patients recovered from lower back pain 
after 10-20 VAX-D sessions or therapy, and the analysis showed randomized risk ratio of 0.17 (95\% 0.03 to 1.05$)$. In Ramos [21] study, one set of patients obtained an average course of treatment consisting of 18 regular sessions, and another group obtained half the number of daily treatment sessions. The treatment parameters for all the patients differed only in terms of the number of sessions while the outcome differed for two groups and found that $67 \%$ of the higher dosage group attained remission of low back pain compared to $43 \%$ of the lower dosage group. The overall static $I^{2}$ was found to be $92 \%$ with an odd's ratio of 0.56 (95\% CI, 0.37 to 0.85$)$. This analysis is seen in Figures 6 and 7.

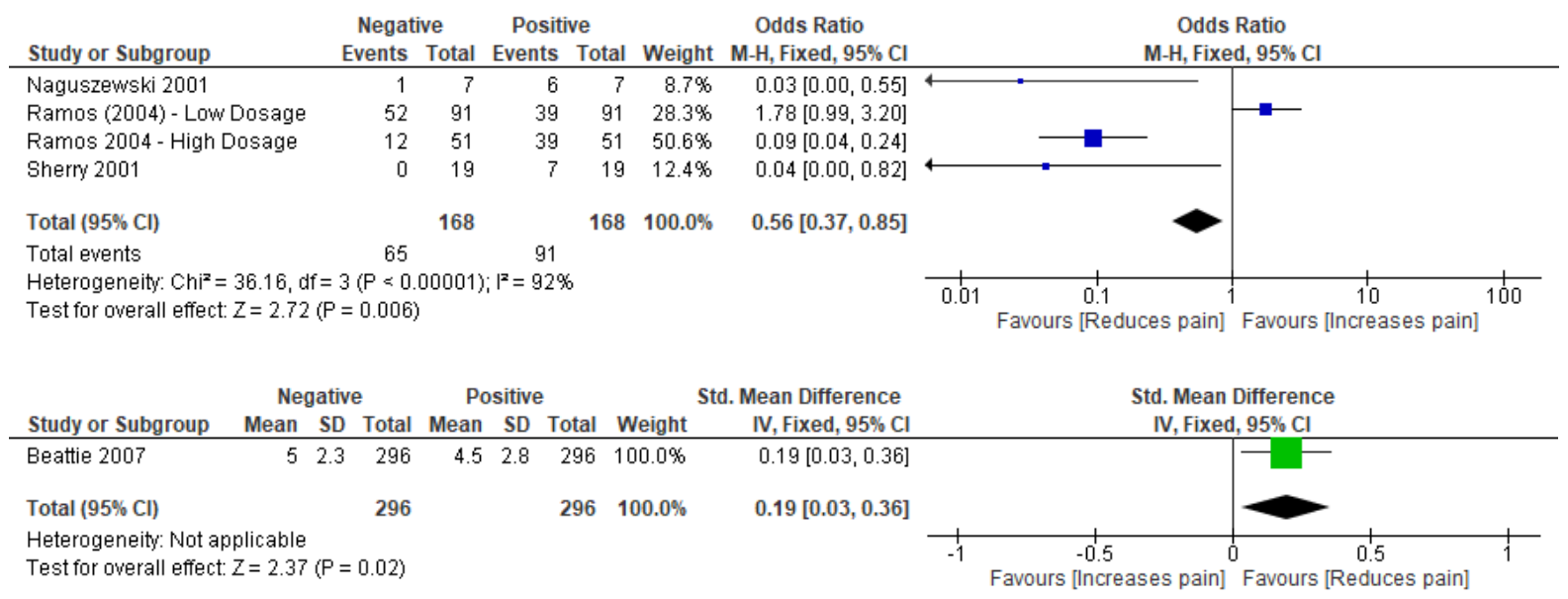

Comparison of groups' pain intensity with pain measurement during follow-up after VAX-D treatment.

Figure 6. Analysis 3: Forest Plot.

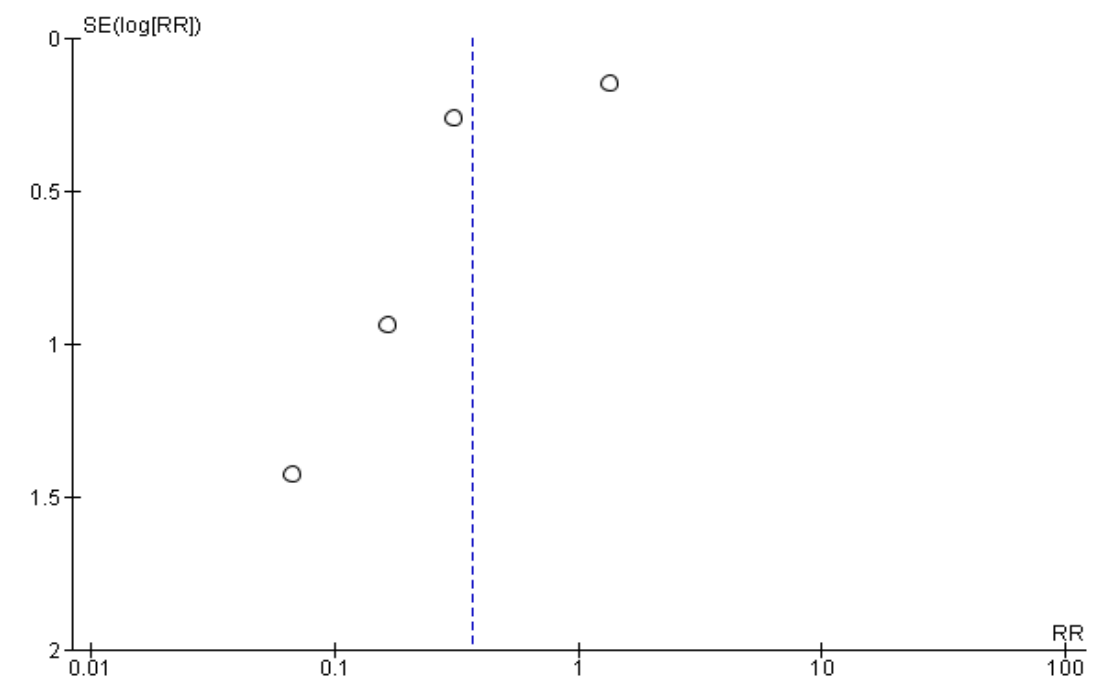

Comparison of groups' pain intensity with pain measurement during follow-up after VAX-D treatment.

Figure 7. Analysis 3: Funnel plot.

\subsection{Adverse Events}

None of the studies reported about adverse events.

\section{Discussion}

In our review, we have determined to use qualitative analysis since many studies failed to provide sufficient data for statistical pooling. It impacts to have false-positive findings with several methodological weaknesses. From this analysis, we observed some conflicting results regarding the effectiveness of VAX-D traction treatment in patients with lower back pain. Our main findings of the study suggest that VAX-D traction for LBP in patients has provided improvement or quality of relief after several sessions of treatment. Beattie et al [23] study was unable to demonstrate the pattern of pain among patients involved in litigation or those receiving compression could be managed using VAXD. The researchers duly noted this generalized limitation. Clinicians administered the sessions as per the VAX-D protocol and no risk of intervention bias. The type of audit conducted was not disclosed, and therefore, there could be some loss to follow-up bias.

In Ramos [21] study, there was no randomization in the 
assignment of participants and activities of daily living were assessed. Also, no data was available on any loss of patients to follow up, and it is difficult to assess the possibility of loss to follow-up bias. The study was more concerned with understanding the mechanism of therapeutic action as opposed to demonstrating the efficacy and safety of VAX-D in treating low back pain.

Sherry et al [32] study reported positive outcomes of posttreatment between VAX-D traction and TENS group of patients. The study has randomization and blinding to minimize bias, but the researchers have noted some difficulty in blinding since the placebo had some effects. The study had excluded only four patients from the original sample and observed the minimal possibility of loss to follow-up bias. This overview described the VAX-D therapy machine and how it was used, and a comparison between VAX-D and traction was made. The overview noted the absence of data on the effectiveness of conventional traction in reducing intradiscal pressure.

Tilaro [33] study, a non-randomized retrospective analysis recorded the patient data. The researchers have appealed that patients have achieved some pain relief without any data, and there was no supporting evidence to state a conclusion on the efficacy of VAX-D in back pain relief. Thus, the report concluded the effectiveness of VAX-D in disc decompression. In this review, we lack robust and consistent evidence regarding the use of traction due to the lack of high-quality studies, the heterogeneity of study populations, and lack of power. Some other studies included hospitalized patients with demonstrated herniated discs, neurological findings, and back pain. Also, some seemed to have had sample sizes that were too small to detect a clinically significant difference. The literature review conveys firmly negative conclusion on traction, in a generalized sense, it is not an effective treatment for LBP patients.

\section{Conclusions}

Studies are more likely to have positive findings with high-quality studies compared to the studies with more methodological weaknesses. Although, some of the highquality studies have shown the positive level of certainty regarding VAX-D traction's in the absence of effective treatment of LBP. Most of the available studies have methodological weaknesses with the potential for biased results. Only 1 of the 6 studies included has obtained the highest quality assessment and fulfilled all the biased outcome trials. Thus, the evidence presented in the studies was weak in several ways. First, there was weak evidence to show VAX-D was equivalent to conservative treatment approaches that have established evidence supporting their efficacy. Secondly, there was no evidence to show VAX-D is superior to conservative treatment options. Finally, there was no evidence to show the dosage requirement, patient position, and settings on the VAX-D table that led to the observed outcomes. Therefore, more studies concerning relevant technique in the treatment of chronic low back pain patients are warranted.

\section{Acknowledgements}

There was no funding or conflicts of interest for this project.

\section{References}

[1] Freburger, J. K., G. M. Holmes, R. P. Agans, A. M. Jackman, J. D. Darter, A. S. Wallace, and T. S. Carey (2009). The rising prevalence of chronic low back pain. JAMA Internal Medicine 169 (3), 251-258.

[2] Myrtos, C. D. (2012). Low back disorders: evidence-based prevention and rehabilitation. Journal of the Canadian Chiropractic Association 56 (1), 76.

[3] Barrey, C. Y. and J. C. Le Huec (2019). Chronic low back pain: Relevance of a new classification based on the injury pattern. Orthopaedics \& Traumatology: Surgery \& Research 105 (2), 339-346.

[4] Manchikanti, L., F. J. Falco, V. Singh, R. M. Benyamin, G. B. Racz, D. L. Caraway, and S. P. Ward (2013). An update of comprehensive evidence-based guidelines for interventional techniques in chronic spinal pain. Part I: introduction and general considerations. Pain Physician 16 (2), S1-48.

[5] Vidyasagar, K., I. Champaign, and L. Manchikanti (2009). The preliminary results of a comparative effectiveness evaluation of adhesiolysis and caudal epidural injections in managing chronic low back pain secondary to spinal stenosis: A randomized, equivalence controlled trial. Pain physician 12, E341-54.

[6] Guevara-López, U., A. Covarrubias-Gómez, J. Elías-Dib, A. Reyes-Sánchez, and T. S. Rodríguez-Reyna (2011). Practice guidelines for the management of low back pain. Cirugia y cirujanos 79 (3), 286-302.

[7] Cheng, J. S., M. J. Lee, E. Massicotte, B. Ashman, M. Gruenberg, L. E. Pilcher, and A. C. Skelly (2011). Clinical guidelines and payer policies on fusion for the treatment of chronic low back pain. Spine 36, S144-S163.

[8] Phillips, F. M., P. J. Slosar, J. A. Youssef, G. Andersson, and F. Papatheofanis (2013). Lumbar spine fusion for chronic low back pain due to degenerative disc disease: a systematic review. Spine 38 (7), E409-E422.

[9] Willems, P. C., J. B. Staal, G. H. Walenkamp, and R. A. de Bie (2013). Spinal fusion for chronic low back pain: systematic review on the accuracy of tests for patient selection. The Spine Journal 13 (2), 99-109.

[10] Barrey, C., J. Jund, O. Noseda, and P. Roussouly (2007). Sagittal balance of the pelvis-spine complex and lumbar degenerative diseases. A comparative study about 85 cases. European Spine Journal 16 (9), 1459-1467.

[11] Van Middelkoop, M., S. M. Rubinstein, T. Kuijpers, A. P. Verhagen, R. Ostelo, B. W. Koes, and M. W. van Tulder (2011). A systematic review on the effectiveness of physical and rehabilitation interventions for chronic non-specific low back pain. European Spine Journal 20 (1), 19-39. 
[12] Harte, A. A., J. H. Gracey, and G. D. Baxter (2005). Current use of lumbar traction in the management of low back pain: results of a survey of physiotherapists in the United Kingdom. Archives of Physical Medicine and Rehabilitation 86 (6), 1164-1169.

[13] Kurutz, M (2006). Age-sensitivity of time-related in vivo deformability of human lumbar motion segments and discs in pure centric tension. Journal of Biomechanics 39 (1), 147-157.

[14] Twomey, L. T (1985). Sustained lumbar traction. An experimental study of long spine segments. Spine 10 (2), 146149.

[15] Diab, A. A., and I. M. Moustafa (2012). Lumbar lordosis rehabilitation for pain and lumbar segmental motion in chronic mechanical low back pain: a randomized trial. Journal of Manipulative \& Physiological Therapeutics 35 (4), 246253.

[16] Onel, D., M. Tuzlaci, H. Sari, and K. L. Demir (1989). Computed tomographic investigation of the effect of traction on lumbar disc herniations. Spine 14 (1), 82-90.

[17] Ramos, G., and W. Martin (1994). Effects of vertebral axial decompression on intradiscal pressure. Journal of Neurosurgery 81 (3), 350-353.

[18] Apfel, C. C., O. S. Cakmakkaya, W. Martin, C. Richmond, A. Macario, E. George, J. V. Pergolizzi (2010). Restoration of disk height through non-surgical spinal decompression is associated with decreased discogenic low back pain: a retrospective cohort study. BMC Musculoskeletal Disorders $11(1), 155$.

[19] Diab, A. A. M., and I. M. Moustafa (2013). The efficacy of lumbar extension traction for sagittal alignment in mechanical low back pain: a randomized trial. Journal of Back Musculoskeletal Rehabilitation 26 (2), 213-220.

[20] Clark, B. C., D. A. Goss, S. Walkowski, R. L. Hoffman, A. Ross, J. S. Thomas (2011). Neurophysiologic effects of spinal manipulation in patients with chronic low back pain. BMC Musculoskeletal Disorders 12 (1), 170.

[21] Ramos, G (2004). Efficacy of vertebral axial decompression on chronic low back pain: study of dosage regimen. Journal of Neuroscience 26 (3), 320-324.

[22] Shealy, C. N (2005). Long-term effect analysis of IDD therapy in low back pian: a retrospective clinical pilot study. American Journal of Pain Management 15, 93-97.

[23] Beattie, P. F., R. M. Nelson, L. A. Michener, J. Cammarata, J. Donley (2008). Outcomes after a prone lumbar traction protocol for patients with activity-limiting low back pain: a prospective case series study. Archives of Physical Medicine and Rehabilitation 89 (2), 269-274.

[24] Wegner, I., I. S. Widyahening, M. W. van Tulder, S. E. Blomberg, H. C. de Vet, G. Brønfort, and G. J. van der Heijden (2013). Traction for low-back pain with or without sciatica. Cochrane Database of Systematic Reviews, https://doi.org/10.1002/14651858.CD003010.pub5.

[25] Clarke, J. A., M. W. van Tulder, S. E. Blomberg, H. C. de Vet, G. J. van der Heijden, G. Brønfort, and L. M Bouter (2007). Traction for low-back pain with or without sciatica. Cochrane Database of Systematic Reviews https://doi.org/10.1002/14651858.CD003010.pub4.

[26] Weber, H (1973). Traction therapy in sciatica due to disc prolapse (does traction treatment have any positive effect on patients suffering from sciatica caused by disc prolapse?). Journal of the Oslo city hospitals 23 (10), 167.

[27] Mathews, J. A., and J. Hickling (1975). Lumbar traction: a double-blind controlled study for sciatica. Rheumatology 14 (4), 222-225.

[28] Reust, P., A. Chantraine, and T. L. Vischer (1988). Treatment of lumbar sciatica with or without neurological deficit using mechanical traction: A double-blind study. Schweizerische medizinische Wochenschrift 118 (8), 271-274.

[29] Cholewicki, J., M. M. Panjabi, and A. Khachatryan (1997). Stabilizing function of trunk flexor-extensor muscles around a neutral spine posture. Spine 22 (19), 2207-2212.

[30] Wang, L., M. Zhao, J. Ma, S. Tian, P. Xiang, W. Yao, and Y. Fan (2014). Effect of combining traction and vibration on back muscles, heart rate and blood pressure. Medical Engineering \& Physics 36 (11), 1443-1448.

[31] Naguszewski, W. K., R. K. Naguszewski, and E. E. Gose (2001). Dermatomal somatosensory evoked potential demonstration of nerve root decompression after VAX-D therapy. Neurol Res 23 (7), 706-714.

[32] Sherry, E., P. Kitchener, and R. Smart (2001). A prospective randomized controlled study of VAX-D and TENS for the treatment of chronic low back pain. Neurological Research 23 (7), $780-784$.

[33] Tilaro, F., and M. D. Miskovich (1999). The Effects of Vertebral Axial Decompression on Sensory Nerve Dysfunction in Patients with Low Back Pain and Radiculopathy. Journal of Clinical and Medical Research 6 (1), 1-10. 